\title{
Multimorbidity associated with polypharmacy and negative self-perception of health
}

\author{
Gustavo Cavalcantil \\ Marlene Doring ${ }^{2}$ \\ Marilene Rodrigues Portella ${ }^{2}$ \\ Emanuelly Casal Bortoluzzi ${ }^{3}$ \\ Andreia Mascarelo $0^{4}$ \\ Marcos Paulo Dellani ${ }^{5}$
}

\section{Abstract}

Objective: to verify the association between the multimorbidity of the elderly and sociodemographic variables, self-perception of health and polypharmacy. Method: a cross-sectional study was performed. The research data was collected using the Health, Well-Being and Aging questionnaire. The sample was composed of 676 people aged 60 years or more, who were residents of small towns in the north of the state of Rio Grande do Sul, Brazil. The dependent variable was multimorbidity, that is, the occurrence of two or more chronic non-communicable diseases in the same person. The independent variables were demographic, socioeconomic and health-related characteristics. Poisson's raw and robust regression model was used to analyze the effect of the independent variables in relation to the outcome and $p$ was considered significant when $<0.05$. Result: among the elderly interviewed, $45 \%$ presented multimorbidity, $51.1 \%$ reported a selfperception of poor/very poor health and $37.1 \%$ used polypharmacy. After the analysis was adjusted to the occurrence of multimorbidity, association with the following variables was found: health perception (regular/poor/very poor) $\mathrm{PR}=1.15$ (CI95\%; $1.09-1.22$ ) and use of polypharmacy $\mathrm{PR}=1.29$ (CI95\%; $1.22-1.35)$. Conclusion: Multimorbidity may interfere negatively in the self-perception of health of the elderly contributing to increased medicine consumption.

\footnotetext{
Universidade de Passo Fundo, Curso Enfermagem. Passo Fundo, RS, Brasil.

2 Universidade de Passo Fundo, Programa Pós Graduação Envelhecimento Humano. Passo Fundo, RS, Brasil.

3 Instituto de Desenvolvimento Educacional do Alto Uruguai, Curso Educação Física. Getúlio Vargas, RS, Brasil.

4 Prefeitura de Coxilha, Secretaria de Saúde, Coxilha, RS, Brasil.

5 Instituto de Desenvolvimento Educacional do Alto Uruguai, Curso Enfermagem. Getúlio Vargas, RS, Brasil.
}

Keywords: Elderly. Comorbidity. Chronic Disease. Health of the Elderly. Polypharmacy. SelfPerception of Health. 


\section{INTRODUCTION}

Aging can lead to the emergence of chronic noncommunicable diseases (CNCDs), and while the process is not directly related to chronic diseases and disabilities, such conditions are more frequent among the elderly ${ }^{1}$.

Among the $\mathrm{CNCDs}$ that affect the elderly, the main illnesses are related to the cardiovascular system, such as Systemic Arterial Hypertension, Cerebrovascular Accidents, and increased glucose rates, which can result in Diabetes Mellitus or cancer ${ }^{2}$. There is also an increased frequency of multiple chronic diseases among such individuals, leading to the presence of multimorbidity among the elderly.

Literature $^{3-6}$ considers multimorbidity the simultaneous occurrence of two or more morbidities, chronic physical or mental diseases in an individual. Individuals with multimorbidity, especially the elderly, tend to experience a greater number of hospitalizations, use multiple medications simultaneously and thereby increase their susceptibility to adverse effects. Thus, the presence of multimorbidity increases the risk of mortality, generates physical and mental problems ${ }^{3-5}$ and negatively influences quality of life ${ }^{7-9}$. It therefore results in greater demands on health care, representing a major challenge for health systems around the world ${ }^{10,11}$, especially as the care involved is more complex ${ }^{12}$.

The complex and challenging ${ }^{11}$ condition of multimorbidity has a major impact on society through the burden it places on the health system and by reducing the productivity of individuals in the labor market and raising the costs of disability ${ }^{13}$. Such data are fundamental to demonstrating the importance of government policies to the health of the elderly. The prevalence of multimorbidity among elderly persons is high (50 to $98 \%)^{10,11}$ and its occurrence is associated with advanced age, the female gender, a low socioeconomic level and an unhealthy lifestyle $e^{14,15}$. In addition, studies indicate that self-perception of health is often described as negative, due to the occurrence of social, physical or mental disabilities, thus impairing quality of life ${ }^{8,9,16,17}$.
The topic is highly relevant, as clinical studies of the elderly often include comorbidity ${ }^{11}$ and information on multimorbidity provides support for the improvement of therapeutic strategies. The present study therefore aimed to verify the association between multimorbidity in the elderly and sociodemographic variables, self-perception of health and polypharmacy.

\section{METHOD}

A cross-sectional population-based study was performed with elderly residents in small municipal regions in the north of the state of Rio Grande do Sul, Brazil. The inclusion criteria were individuals aged 60 and over, of both genders, who had lived in rural or urban areas in the municipal regions of Coxilha and Estação for at least six months, and had, at the time of the interview, cognitive conditions to respond to the questionnaire, and/or the presence of a relative or caregiver to assist them or provide answers. Elderly persons hospitalized at the time of the interview were excluded.

A prevalence of the outcome (multimorbidity) of $45 \%{ }^{18}$, a sample error of $5 \%$, a confidence interval of $95 \%$ and a power of $80 \%$ were used to calculate the sample size, and provided a result of 381 elderly persons. This total was multiplied by 1.5 for the design effect, resulting in 571 elderly persons. A total of $10 \%$ was then added to the total to allow for possible losses (refusals and non-eligibility, among other factors), giving a total of 628 elderly persons. However, as there were other outcomes with a larger sample, the decision was taken to include 676 elderly persons.

All the elderly persons in the municipal region of Coxilha (352) were included in the study. There was a loss of $6 \%$ (21), giving a total of 331 individuals. To make up the sample, 345 of the 992 elderly persons living in the municipality of Estação were randomly added. These individuals were initially listed by area of residence and gender, and were subsequently selected by simple random sampling, maintaining the proportions of gender and area of residence in the total elderly population (Figure 1). 


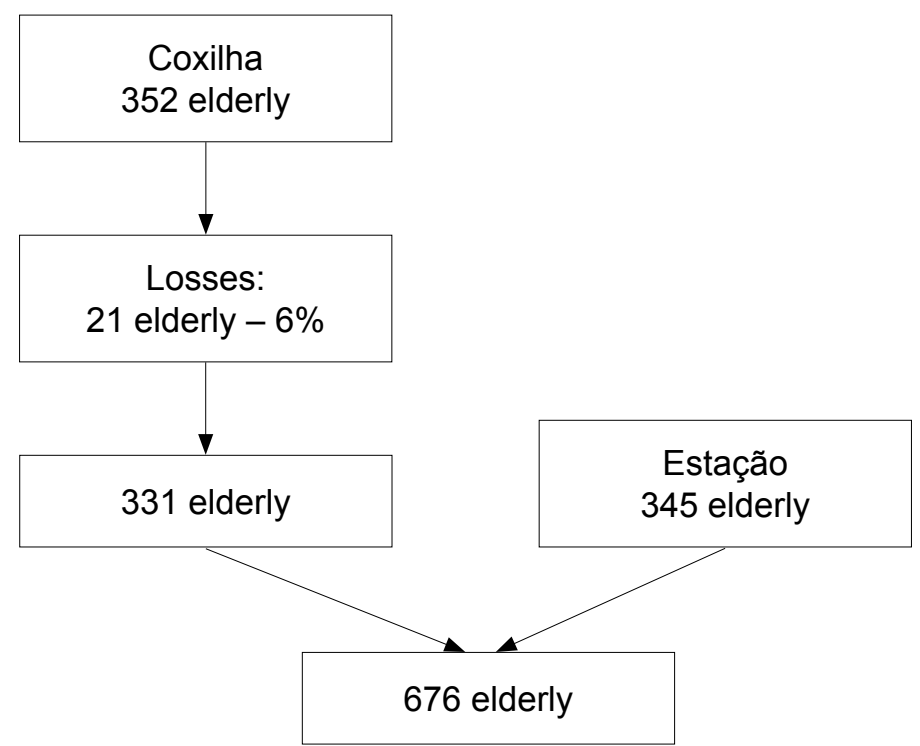

Figure 1. Flowchart of sample selection. Coxilha, Estação, Rio Grande do Sul, Brazil. 2010, 2011.

Data collection was carried out from 2010 to 2011 through a household survey, using the Pesquisa, Saúde, Bem Estar e Envelhecimento (Research, Health, Well-being and Aging) (SABE) structured questionnaire. Although this instrument has seven sections, only the following parts were used in the present study: a) Personal and family information, c) Housing conditions, d) Health conditions and living habits, and f) Use and access to health services.

Multimorbidity, defined as two or more chronic diseases occurring simultaneously in an individual, was considered the dependent variable. As the list of morbidities included in this definition has not yet been established in literature, those measured in SABE Section D (Health conditions and living habits) were included, with the following diseases considered: systemic arterial hypertension, diabetes mellitus, rheumatism, asthma or bronchitis and pulmonary emphysema, stroke/cerebral ischemia, arthritis/osteoporosis, heart problems (coronary disease, angina, congestive disease, others) and depression.

The following variables were considered: gender (female and male), age group (60-79 and 80 years or older), schooling (attended school and did not attend school), skin color/ethnicity (white and non-white), marital status (with spouse (married or lives with partner) or without spouse (widowed, single, separated and divorced), family income $(\leq 1$ minimum wage or $>1$ minimum wage), place of residence (urban or rural) and engages in physical activity (yes or no).

For the variable physical activity, the elderly persons were asked if they engaged in some kind of physical activity in their day to day lives (domestic, work and/or leisure activities), with the question explained and exemplified so that they could understand and classify whether or not they practiced physical activity. Polypharmacy (yes or no) was defined as elderly persons who said they took five or more medications a day.

For alcohol ingestion (yes and no), the elderly persons were asked on how many days per week, on average, they had drunk alcohol over the last three months. Individuals who responded "one or two days a week", "three or four days a week", or "every day of the week" were categorized as "yes". Habit of Smoking was classified as yes or no, while Perception of Health was divided into good/very good or fair/poor/very poor). 
Categorical variables (nominal and ordinal) were presented as absolute and relative frequency distributions. Quantitative variables were described by measures of central tendency and variability. Bivariate analysis using the chi-squared test was used evaluate the association between multimorbidity and the independent variables, with a significance level of $5 \%$. Prevalence ratios and $95 \%$ confidence intervals were used in the crude and adjusted analysis, both of which used Poisson regression. Variables with a $p$ value less than 0.20 in bivariate analysis were considered in the multiple model, while those with $p<0.05$ remained in the model.

The study was approved by the Ethics Research Committee of the Universidade de Passo Fundo (the University of Passo Fundo) under opinion numbers 148/2010 (Coxilha) and 017/2011 (Estação), in accordance with the guidelines of Resolution $n^{\circ}$ 196/96 of the National Health Council.

\section{RESULTS}

A total of 676 elderly people, who were predominantly female $(54.6 \%)$, participated in the study. The mean age was 70 years $( \pm 7.63)$, and of the sample $78.4 \%$ described themselves as white; $15 \%$ had attended school; $71.4 \%$ had a spouse, $88.9 \%$ had an income greater than or equal to one minimum wage and $69.4 \%$ lived in the urban area. In terms of health, 45\% presented multimorbidity, 49.4\% did not engage in physical activity; $27.1 \%$ used polypharmacy; 67.6\% ingested alcoholic beverages; $14.4 \%$ were smokers, $47.2 \%$ described their self-perceived health as poor/very poor; and the majority (98\%) had access to health services, as shown in Table 1.

The prevalence of multimorbidity in the elderly was $45 \%$. Of those affected by this outcome $50.9 \%$ were female, $60 \%$ were over 80 years old, $47.9 \%$ were non-white, $48 \%$ went to school, $51.8 \%$ had no spouse, $45.5 \%$ had an income of more one minimum wage, $69.4 \%$ lived in urban areas, $53.3 \%$ did not engage in physical activity, $86 \%$ used polypharmacy, $52.9 \%$ drank alcohol, $45.8 \%$ did not smoke and $63.7 \%$ perceived their health as regular/poor/very poor (Table 2).

In crude analysis multimorbidity was associated with the following variables: gender $(p=0.001)$, age range $(p=0.002)$, marital status $(p=0.033)$, family income $(p<0.001)$, polypharmacy $(p \leq 0.001)$, alcohol intake $(p \leq 0.001)$ and health perception $(p \leq 0.001)$. In the adjusted analysis of multimorbidity among the elderly, the outcome remained associated with polypharmacy $(p \leq 0.001)$ and health perception ( $p \leq 0.001)$ (Table 2). 
Table 1. Sociodemographic and behavioral characteristics of elderly persons. Rio Grande do Sul, 2010/2011.

\begin{tabular}{|c|c|c|c|}
\hline Variable & $\mathrm{n}$ & Prevalence $(\%)$ & CI 95\% \\
\hline \multicolumn{4}{|l|}{ Gender } \\
\hline Female & 369 & 54.6 & $50.6-58.3$ \\
\hline Male & 307 & 45.4 & $41.7-49.4$ \\
\hline \multicolumn{4}{|l|}{ Age range (years) } \\
\hline $60-79$ & 596 & 88.2 & $85.7-90.8$ \\
\hline 80 or older & 80 & 11.8 & $9.2-14.3$ \\
\hline \multicolumn{4}{|l|}{ Skin color } \\
\hline White & 530 & 78.4 & $75.1-81.2$ \\
\hline Non-White & 146 & 21.6 & $18.8-24.9$ \\
\hline \multicolumn{4}{|l|}{ Level of schooling } \\
\hline Did not attend school & 573 & 85.0 & $12.3-17.8$ \\
\hline Attended school & 101 & 15.0 & $82.2-87.7$ \\
\hline \multicolumn{4}{|l|}{ Marital status } \\
\hline With spouse & 193 & 28.6 & $25.1-32.2$ \\
\hline Without spouse & 483 & 71.4 & $67.8-74.9$ \\
\hline \multicolumn{4}{|c|}{ Family income (minimum salary) } \\
\hline$\leq 1$ & 73 & 11.1 & $8.8-13.7$ \\
\hline$>1.01$ & 584 & 88.9 & $86.3-91.2$ \\
\hline \multicolumn{4}{|c|}{ Engages in physical activity } \\
\hline Yes & 341 & 50.5 & $45.8-53.0$ \\
\hline No & 334 & 49.5 & $47.0-54.2$ \\
\hline \multicolumn{4}{|l|}{ Polypharmacy } \\
\hline Yes & 164 & 27.8 & $24.4-31.6$ \\
\hline No & 425 & 72.2 & $68.4-75.6$ \\
\hline \multicolumn{4}{|l|}{ Consumes alcohol } \\
\hline Yes & 456 & 67.6 & $64.1-71.1$ \\
\hline No & 219 & 32.4 & $28.9-35.9$ \\
\hline \multicolumn{4}{|l|}{ Smokes } \\
\hline Yes & 97 & 14.4 & $11.9-17.1$ \\
\hline No & 577 & 85.6 & $82.9-88.1$ \\
\hline \multicolumn{4}{|l|}{ Multimorbidity } \\
\hline Yes & 304 & 45.0 & $51.3-58.8$ \\
\hline No & 371 & 55.0 & $41.2-48.7$ \\
\hline \multicolumn{4}{|l|}{ Perception of health } \\
\hline Good/very good & 356 & 52.8 & $49.1-56.4$ \\
\hline Fair/poor/very poor & 318 & 47.2 & $43.6-50.9$ \\
\hline \multicolumn{4}{|l|}{ Area of residence } \\
\hline Urban & 469 & 69.4 & $65.8-73.1$ \\
\hline Rural & 207 & 30.6 & $26.9-34.2$ \\
\hline
\end{tabular}


Table 2. Prevalence of multimorbidity and associated factors among the elderly. Rio Grande do Sul, 2010/2011.

\begin{tabular}{|c|c|c|c|c|c|}
\hline Variable & $\mathrm{N}$ & Prevalence $(\%)$ & $\mathrm{p}$ & PR (CI 95\%) & *PR (CI 95\%) \\
\hline Gender & & & 0.001 & & \\
\hline Female & 369 & 50.9 & & $1.09(0.87-0.96)$ & --- \\
\hline Male & 307 & 37.9 & & & \\
\hline Age range (years) & & & 0.002 & & \\
\hline 80 or older & 80 & 60.0 & & $1.20(1.04-1.20)$ & --- \\
\hline $60-79$ & 596 & 43.0 & & & \\
\hline Skin color & & & 0.423 & & \\
\hline White & 530 & 44.2 & & $1.03(0.96-1.09)$ & --- \\
\hline Non-White & 146 & 47.9 & & & \\
\hline Level of schooling & & & 0.494 & & \\
\hline Attended school & 573 & 48.0 & & $1.02(0.95-1.10)$ & --- \\
\hline Did not attend school & 101 & 44.3 & & & \\
\hline Marital status & & & 0.033 & & \\
\hline With spouse & 193 & 51.8 & & $1.06(1.00-1.12)$ & --- \\
\hline Without spouse & 483 & 42.3 & & & \\
\hline Family income (minimum salary) & & & 0.194 & & \\
\hline$\leq 1$ & 584 & 37.5 & & & \\
\hline$>1,01$ & 73 & 45.5 & & $1.06(0.97-1.15)$ & --- \\
\hline \multicolumn{6}{|l|}{ Area of residence } \\
\hline Urban & 469 & 69.4 & 0.226 & $1.03(0.98-1.10)$ & --- \\
\hline Rural & 207 & 30.6 & & & \\
\hline Engages in physical activity & & & $<0.001$ & & \\
\hline No & 334 & 53.3 & & $1.12(1.06-1.17)$ & --- \\
\hline Yes & 341 & 37.0 & & & \\
\hline Polypharmacy & & & $<0.001$ & & \\
\hline Yes & 164 & 86.0 & & $1.36(1.30-1.42)$ & $1.29(1.22-1.35)$ \\
\hline No & 425 & 36.7 & & & \\
\hline Consumes alcohol & & & $<0.001$ & & \\
\hline Yes & 456 & 52.9 & & $1.15(1.08-1.23)$ & --- \\
\hline No & 219 & 28.8 & & & \\
\hline Smokes & & & 0.231 & & \\
\hline Yes & 97 & 40.2 & & $0.95(0.88-1.03)$ & --- \\
\hline No & 577 & 45.8 & & & \\
\hline Perception of health & & & $<0.001$ & & \\
\hline Fair/poor/very poor & 318 & 63.7 & & $1.24(1.17-1.30)$ & $1.15(1.09-1.21)$ \\
\hline Good/very good & 356 & 28.1 & & & \\
\hline
\end{tabular}

PR: prevalence ratio; $*$ PR adjusted prevalence ratio; CI: 95\% confidence interval; $p$ : Pearson's chi-squared test.

The prevalence ratio of elderly persons with multimorbidity who reported their health as regular/ poor/very poor was 1.15 times higher than that of the elderly who reported their health as good/ very good. Furthermore, the prevalence ratio of elderly individuals with multimorbidity who used polypharmacy was 1.29 times higher than those who did not use polypharmacy. 


\section{DISCUSSION}

The prevalence of multimorbidity found in the elderly population was $45 \%$, a rate lower than that found in systematic review studies in which the prevalence was between 50 and $98 \% \%^{1,19}$. These differences can be explained by the different forms of analyzing the prevalence of multimorbidity of the studies, making evaluation of the outcome difficult, mainly due to the lack of a standard in relation to the number of diseases to be considered. While the occurrence of two or more chronic diseases is frequently used ${ }^{20}$, the number of chronic conditions evaluated in studies ranges from 5 to 335 , with a subsequent variation in the prevalence of multimorbidity ${ }^{19}$.

The location where the studies were conducted may also have influenced the results, as the main surveys were often performed in large urban centers $^{21}$. The outcome of multimorbidity was not associated with the place of residence in systematic analysis, however ${ }^{19}$.

Similarly, the method used for the analysis of the association of multimorbidity may have interfered with the results. Poisson logistic regression analysis was employed in the present study, which demonstrated significant differences with results found in literature, where multimorbidity was frequently related to female gender, advanced age, low socioeconomic level and physical inactivity, as well as mental disorders? ${ }^{7}$. This test was performed using both crude and adjusted models, and the variables highlighted in literature were found to be associated in the crude model. However, polypharmacy and self-perception of health remained associated with the outcome in the adjusted analysis.

A self-perception of health as regular/poor/ very poor was reported by most of the elderly with multimorbidity, and was associated with the outcome. Other studies found the same results ${ }^{9,17}$. This finding can be explained by studies that show that elderly people with multimorbidity have a poorer quality of life, a deficit in self-care of health, and a greater degree of dependence in daily life, with negative repercussions on functional capacity ${ }^{22}$. As the number of diseases increases, physical, social and mental complications occur in the elderly, resulting in a worsening of self-perception of health ${ }^{23}$.

The use of polypharmacy was also associated with multimorbidity. This association can be understood by the frequent need among the elderly to take medications for the treatment of diseases. The seeking out of medical care due to the clinical manifestations of disease, the fragmented care of elderly persons with multimorbidity, the health protocols aimed at a single disease ${ }^{11}$, and the difficulty of deciding treatment in a shared manner among health professionals and in providing patientcentered care ${ }^{24}$ may be elements that contribute to the frequent use of medications by the elderly.

This uncontrolled consumption may also cause clinical alterations, or even drug interactions which have adverse effects on the elderly ${ }^{22,25}$. Understanding how morbidities interact with one another has a greater clinical relevance than simply counting the number of diseases. From this knowledge, it is possible to determine the possible drug interactions to which elderly persons are exposed ${ }^{11}$. Studies on medications often exclude elderly patients with multimorbidity, making it difficult for medical professionals to determine appropriate treatment ${ }^{26}$. However, the geriatrician, when participating in treatment with a multidisciplinary team, can maintain or decrease the number of medications used by patients ${ }^{27}$. Additionally, the use of methods described in literature, such as that proposed by BEERS (which allows the evaluation of the suitability of drugs used by the elderly), avoids the use of potentially inappropriate medications ${ }^{28}$.

\section{CONCLUSION}

It can be concluded that multimorbidity is associated with a negative self-perception of health and polypharmacy. Faced with the progressive aging of the population, special attention should be given to elderly persons with multimorbidity, with a focus on health interventions aimed not just at treating chronic diseases but also the promotion of an improved quality of life. 


\section{REFERENCES}

1. Marengoni A, Angleman S, Melis R, Mangialasche F, Karp A, Garmen A. Aging with multimorbidity: a systematic review of the literature. Ageing Res Rev. 2011;10(4):430-9.

2. Ministério da Saúde. Plano de Ações Estratégicas para o Enfrentamento das Doenças Crônicas Não Transmissíveis (DCNT) no Brasil 2011-2022 [Internet]. Brasília, DF: MS; 2011. [acesso em 20 jan. 2017]. Disponível em: http://bvsms.saude.gov.br/bvs/ publicacoes/plano_acoes_enfrent_dcnt_2011.pdf

3. Boyd CM, Fortin M. Future of multimorbidity research: how should understanding of multimorbidity inform health system design? Public Health Rev. 2010;32(2):451-74.

4. Barnett K, Mercer SW, Norbury M, Watt G, Wyke S, Guthrie B. Epidemiology of multimorbidity and implications for health care, research, and medical education: a cross-sectional study. Lancet. 2012;380(9836):37-43.

5. Salive ME. Multimorbidity in older adults. Epidemiol Rev. 2013;1(1):75-83.

6. Lefèvre T, D'ivernois JF, De Andrade V, Crozet C, Lombrail P, Gagnayre R. What do we mean by multimorbidity? an analysis of the literature on multimorbidity measures, associated factors, and impact on health services organization. Rev Epidemiol Santé Publique. 2014;62(5):305-14.

7. Organização Mundial de Saúde. Estatísticas da Saúde Mundial 2011. Geneva: OMS; 2011.

8. Lima-costa MF, Facchini LA, Matos DL, Macinko J. Tendências em dez anos das condições de saúde de idosos brasileiros: evidências da Pesquisa Nacional por Amostra de Domicílios (1998 - 2008). Rev Saúde Pública. 2012;46(1):100-7.

9. Alaba O, Chola L. The social determinants of multimorbidity in South Africa. Int J Equity Health. 2013;12(1):63-73.

10. Vos T, Flaxman AD, Naghavi M, Lozano R, Michaud C, Ezzati M, et al. Years lived with disability (YLDs) for 1160 sequelae of 289 diseases and injuries 1990-2010: a systematic analysis for the Global Burden of Disease Study 2010. Lancet. 2013;380(9859):2163-96.

11. Batista SR. A complexidade da multimorbidade. J Manag Prim Health Care. 2014;5(1):125-6.

12. Cheung CL, Nguyen USDT, Au E, Tan KCB, Kung AWC. Association of handgrip strength with chronic diseases and multimorbidity. Age. 2013;35(3):929-41.
13. Organização Mundial de Saúde. Estatísticas da Saúde Mundial 2013. Geneva: OMS; 2013.

14. Wang HH, Wang JJ, Wong SY, Wong MC, Li FJ, Wang PX, et al. Epidemiology of multimorbidity and implications for healthcare: Cross-sectional survey among 162,464 community household residents in southern China. BMC med. 2014;12(1):188-99.

15. Nunes BP, Thumé E, Facchini LA. Multimorbidity in older adults: magnitude and challenges for the Brazilian health system. BMC Public Health. 2015;15(1):1172-82.

16. $\mathrm{Ng} \mathrm{CW}$, Luo N, Heng BH. Health status profiles in community-dwelling elderly using self-reported health indicators: a latent class analysis. Quality Life Res. 2014;23(10):2889-98.

17. Pimenta FB, Pinho L, Silveira MF, Botelho ACDC. Fatores associados a doenças crônicas em idosos atendidos pela Estratégia de Saúde da Família. Ciênc Saúde Coletiva. 2015;20(8):2489-98.

18. Jerliu N, Toci E, Burazeri G, Ramadani N, Brand H. Prevalence and socioeconomic correlates of chronic morbidity among elderly people in Kosovo: a population-based survey. BMC Geriatr. 2013;13(1):22.

19. Violán C, Forguet-Boreu Q, Flores-mateo G, Salisbury C, Blom J, Freitag M, et al. Prevalence, determinants and patterns of multimorbidity in primary care: a systematic review of observational studies. PloS ONE. 2014;9(7):102-49.

20. Arokiasamy P, Uttamacharya U, Jain K, Biritwum R B, Yawson AE, Wu F, et al. The impact of multimorbidity on adult physical and mental health in low-and middle-income countries: what does the study on global ageing and adult health (SAGE) reveal? BMC Med. 2015;13(1):178.

21. Smith SM, Soubhi H, Fortin M, Hudon C, O’Dowd T. Managing patients with multimorbidity: systematic review of interventions in primary care and community settings. BMJ Open. 2012;345:2-10.

22. Huntley A L, Johnson R, Purdy S, Valderas JM, Salisbury C. Measures of multimorbidity and morbidity burden for use in primary care and community settings: a systematic review and guide. Ann Fam Med. 2012;10(2):134-41.

23. Organização Mundial de Saúde. Relatório mundial de envelhecimento e saúde. Geneva: OMS; 2015.

24. Sinnott C, Mc Hugh S, Browne J, Bradley C. GPs' perspectives on the management of patients with multimorbidity: systematic review and synthesis of qualitative research. BMJ Open. 2013;3(9):1-12. 
25. Pavão ALB, Werneck GL, Campos MR. Autoavaliação do estado de saúde e a associação com fatores sociodemográficos, hábitos de vida e morbidade na população: um inquérito nacional. Cad Saúde Pública. 2013:29(4):723-34.

26. Broeiro P. Multimorbilidade e comorbilidade: duas perspectivas da mesma realidade. Rev Port Med Geral Fam. 2015;31(3):158-60.
27. Regueiro M, Mendy N, Cañás M, Farina HO, Nagel P. Uso de medicamentos en adultos mayores no institucionalizados. Rev Peru Med Exp Salud Publica. 2011;28(4):643-47.

28. Campanelli CM. American Geriatrics Society updated beers criteria for potentially inappropriate medication use in older adults: the American Geriatrics Society 2012 Beers Criteria Update Expert Panel. J Am Geriatr Soc. 2012;60(4):616-31.

Received: July 01, 2017

Reviewed: July 18, 2017

Accepted: August 29, 2017 


\section{ERRATUM}

The name of the sixth author of the article "Multimorbidity associated with polypharmacy and negative selfperception of health", published on P.634 of the Revista Brasileira de Geriatria e Gerontologia v. 20, n. 5, p. 634-642, 2017, DOI: http://dx.doi.org/10.1590/1981-22562017020.170059, was listed incorrectly. The correct name of this author is Marcos Paulo Dellani, and not Marcos Paulo Delani as printed. 